\title{
A comparison of hepatitis B seroepidemiology in ten European countries
}

A. NARDONE ${ }^{1 *}$, C. G. ANASTASSOPOULOU ${ }^{2}$, H. THEETEN ${ }^{3}$, B. KRIZ ${ }^{4}$, I. DAVIDKIN ${ }^{5}$, W. THIERFELDER ${ }^{6}$, D. O'FLANAGAN ${ }^{7}$, B. BRUZZONE ${ }^{8}$, J. MOSSONG ${ }^{9}$, H. J. BOOT ${ }^{10}$, D. BUTUR ${ }^{11}$, M. SLAČIKOVÁ ${ }^{12}$, M. L. C. PANAIT ${ }^{11}$, W. HELLENBRAND ${ }^{6}$, H. DE MELKER ${ }^{10}$, Z. SOBOTOVÁ ${ }^{12}$, G. ICARDI $^{8}$, N. ANDREWS ${ }^{1}$, R. G. PEBODY ${ }^{1}$, P. VAN DAMME ${ }^{3}$, G. KAFATOS ${ }^{1}$, E. MILLER ${ }^{1}$ AND A. HATZAKIS ${ }^{2}$

${ }^{1}$ Centre for Infections, Health Protection Agency, London, UK; ${ }^{2}$ National Retrovirus Reference Centre, Department of Hygiene and Epidemiology, University of Athens Medical School, Athens, Greece; ${ }^{3}$ Centre for the Evaluation of Vaccination, Vaccine \& Infectious Disease Institute, University of Antwerp, Antwerp, Belgium;

${ }^{4}$ National Institute for Public Health, Prague, Czech Republic; ${ }^{5}$ National Public Health Institute, Helsinki, Finland; ${ }^{6}$ Robert Koch-Institute, Berlin, Germany; ${ }^{7}$ Health Protection Surveillance Centre, Dublin, Ireland; ${ }^{8}$ Department of Health Sciences, University of Genoa, Genoa, Italy $;{ }^{9}$ Laboratoire National de Santé, Luxembourg; ${ }^{10}$ Centre for Infectious Disease Control, National institute of Public Health and the Environment (RIVM), Bilthoven, The Netherlands; ${ }^{11}$ National Institute for Research and Development in Microbiology and Immunology 'Cantacuzino', Bucharest, Romania; ${ }^{12}$ Public Health Authority of the Slovak Republic, Bratislava, Slovak Republic

(Accepted 7 November 2008; first published online 23 December 2008)

\section{SUMMARY}

To inform current and future vaccination strategies, we describe the seroepidemiology of hepatitis B virus (HBV) infection in ten representative European countries using standardized serology that allowed international comparisons. Between 1996 and 2003, national serum banks were compiled by collecting residual sera or by community sampling; sera were then tested by each country using its preferred enzyme immunoassays and testing algorithm, and assay results were standardized. Information on current and past $\mathrm{HBV}$ vaccination programmes in each country was also collected. Of the ten countries, six reported low levels $(<3 \%)$ of antibodies against HBV core antigen (anti-HBc). Of the eight countries testing for HBV surface antigen (HBsAg), the highest prevalence was reported in Romania $(5.6 \%)$ and in the remaining seven countries prevalence was $<1 \%$. Universal HBV vaccination programmes had been established in seven countries as recommended by the World Health Organization, but the seroprevalence of antibodies against $\mathrm{HBsAg}$ (anti-HBs) was lower than the reported vaccine coverage in three countries. Regular serological surveys to ascertain HBV status within a population, such as reported here, provide important data to assess the need for and to evaluate universal HBV vaccination programmes.

Key words: Europe, hepatitis B, serology, vaccination.

\footnotetext{
* Author for correspondence: Dr A. Nardone, Centre for Infections, Health Protection Agency, 61 Colindale Avenue, London NW9 5EQ, UK.

(Email: anthony.nardone@hpa.org.uk)
} 


\section{INTRODUCTION}

Infection with hepatitis B virus (HBV) is a problem of global public health importance. The failure of individuals to clear HBV leads to a chronic infection, characterized by carriage of the HBV surface antigen (HBsAg), a marker of infectivity as well as possible progression to end-stage hepatic diseases such as cirrhosis or primary hepatocellular carcinoma [1].

The Regional Office for Europe of the World Health Organization (WHO) has estimated that in Europe each year one million people become infected with HBV, and of these 90000 evolve to a chronic carrier state and more than 22000 die of cirrhosis or hepatocellular carcinoma [2]. The prevalence of HBsAg, which is influenced primarily by the age at infection, has been used to categorize endemicity as high $(\geqslant 8 \%)$, intermediate $(2-8 \%)$, low $(<2 \%)$ [3] or very low $(<0 \cdot 5 \%)$ [4]. In Europe, there are wide variations in reported HBsAg carriage, increasing west to east and north to south [3]. This geographical variation is reflected in the estimated mortality from cirrhosis and hepatocellular carcinoma due to HBV, with about 200 attributable deaths annually in northwestern Europe compared to nearly 19000 in central and eastern Europe [2].

$\mathrm{HBV}$ is a possible candidate disease for elimination and ultimately eradication as the reservoir for HBV is entirely human and highly efficacious preventative vaccines are available [5]. In 1991, the WHO called on all countries to introduce universal $\mathrm{HBV}$ vaccination by 1997 [6]. By the end of 2004, universal HBV vaccination programmes were in place in 43 of the 52 countries in the WHO European region [7]. Some countries in northern and western Europe, where endemicity is low, have not implemented universal HBV vaccination programmes [4] but rather selective immunization programmes $[8,9]$ targeting migrant populations and at-risk groups $[10,11]$.

Serological surveillance is a vital tool for assessing the burden of infection and thus the need for a vaccination programme as well as the evaluation of such programmes once they are in place. The use of an algorithm testing for HBsAg as well as antibodies to surface (anti-HBs) and core (anti-HBc) antigens enables serological studies to estimate the prevalence of carriers, resolved infection and vaccinated individuals in a population [3]. Thus, serological data can supplement HBV disease surveillance data, which are limited because of underreporting of acute and chronic cases, the long incubation between infection and disease as well as the large proportion of asymptomatic acute cases, especially in children.

The European Sero-Epidemiology Network (ESEN2), based on the previous ESEN project [12], was established in 2001 with the aim of standardizing serological surveillance to eight vaccine-preventable diseases, of which one was HBV infection, in 22 European countries [13]. Variations in antibody titres have been reported between laboratories, even those using the same assay $[14,15]$. Thus, the standardization of assay results was essential to allow international comparisons of HBV serology. We present the comparison of HBV seroepidemiology in the ten participant countries in order to describe the epidemiology of HBV infection in Europe in relation to vaccine policy, to inform the development of the most appropriate control measures and to evaluate vaccination programmes in place.

\section{METHODS}

\section{Serum survey collection}

As part of ESEN2, ten countries undertook testing for HBV antibody and antigens in sera specimens collected between 1996 and 2003 (Table 1). The sera were obtained either by residual sera collected during routine laboratory testing (6/10 countries) or by population-based random sampling (4/10) (Table 1). Ethical approval was sought from the appropriate national authorities for all collections.

Sera were evenly distributed between males and females and were geographically representative of each country. Project guidelines recommended that $>3000$ samples should be tested from all age groups, of which two-thirds were from those aged $<20$ years [12]. Sera were collected in all age groups except in Belgium (only those aged $<20$ years), Germany (from 17 to $\geqslant 60$ years) and Luxembourg (from 4 to $\geqslant 60$ years) (Table 2). Furthermore, smaller than recommended sample sizes were collected in the Czech Republic (2644 samples tested), Ireland (2535) and Romania (1338) (Table 2).

\section{Organizational analysis}

In March 2002, a standardized questionnaire requesting historical information regarding the HBV vaccination programmes was sent to all national representatives. Reported infant HBV vaccination coverage was updated with data reported to the 
Table 1. Childhood vaccination policies for hepatitis B, national serum bank collection and serological testing algorithms employed in the ten participant countries in ESEN2

\begin{tabular}{|c|c|c|c|c|c|c|c|c|c|}
\hline & \multicolumn{3}{|c|}{$\begin{array}{l}\text { Childhood HBV } \\
\text { vaccination programmes }\end{array}$} & & & & & & \\
\hline & \multirow[b]{2}{*}{ Type } & \multirow[b]{2}{*}{$\begin{array}{l}\text { Year of } \\
\text { introduction }\end{array}$} & \multirow{2}{*}{$\begin{array}{l}\text { Age of } \\
\text { adolescent } \\
\text { catch-up } \\
\text { (yr) }\end{array}$} & \multicolumn{3}{|c|}{ National Serum Bank } & \multicolumn{3}{|c|}{ HBV testing algorithm } \\
\hline & & & & $\begin{array}{l}\text { Method of } \\
\text { collection }\end{array}$ & $\begin{array}{l}\text { Year of } \\
\text { collection }\end{array}$ & $\begin{array}{l}\text { Years } \\
\text { elapsed } \dagger\end{array}$ & $\begin{array}{l}\text { Anti- } \\
\mathrm{HBc}\end{array}$ & $\begin{array}{l}\text { Anti- } \\
\text { HBs }\end{array}$ & HbsAg \\
\hline Belgium & Universal & 1999 & $11-12$ & Residual & $2002 / 2003$ & $3 / 4$ & + & + & Anti-HBc + \\
\hline Czech Republic & Universal & 2001 & 12 & Population & 2001 & 0 & + & + & Anti-HBc + \\
\hline Germany & Universal & 1995 & $9-17$ & Residual & 1998 & 3 & + & + & —* \\
\hline Italy & Universal & 1991 & 12 & Residual & 1996 & 5 & + & + & Anti-HBc+ \\
\hline Luxembourg $\dagger$ & Universal & 1996 & 12 & Population & $2000 / 2001$ & $4 / 5$ & + & $+t$ & - \\
\hline Romania & Universal & 1995 & 9 & Residual & 2002 & 7 & + & + & Anti-HBc + \\
\hline Slovakia & Universal & 1998 & 12 & Population & 2002 & 6 & + & + & Anti-HBc + \\
\hline Finland & Targeted & - & - & Residual & 1997/1998 & - & + & - & Anti-HBc + \\
\hline Ireland & Targeted & - & - & Residual & 2003 & - & + & - & Anti-HBc + \\
\hline The Netherlands & Targeted & - & - & Population & 1995/1996 & - & + & - & Anti-HBc + \\
\hline
\end{tabular}

* Years elapsed between introduction of vaccination programme and serum bank collection.

$\dagger$ All anti-HBc samples were tested for HBsAg but data unavailable.

$\$$ All samples tested for anti-HBs antibody, of which only positives were tested for anti-HBc antibodies.

Table 2. Age-specific seroprevalence of anti-HBc-positive and HBSAg-positive samples in ten ESEN2 countries, $1996-2003$

\begin{tabular}{|c|c|c|c|c|c|c|c|c|c|c|c|c|}
\hline & \multicolumn{3}{|l|}{ Total } & \multicolumn{3}{|c|}{$1-15$ years } & \multicolumn{3}{|c|}{ 16-39 years } & \multicolumn{3}{|c|}{$\geqslant 40$ years } \\
\hline & $\begin{array}{l}\% \\
\text { anti- } \\
\mathrm{HBc}\end{array}$ & $\begin{array}{l}\% \\
\text { HBsAg }\end{array}$ & $N$ & $\begin{array}{l}\% \\
\text { anti- } \\
\mathrm{HBc}\end{array}$ & $\begin{array}{l}\% \\
\text { HBsAg }\end{array}$ & $N$ & $\begin{array}{l}\% \\
\text { anti- } \\
\mathrm{HBc}\end{array}$ & $\begin{array}{l}\% \\
\mathrm{HBsAg}\end{array}$ & $N$ & $\begin{array}{l}\% \\
\text { anti- } \\
\mathrm{HBc}\end{array}$ & $\begin{array}{l}\% \\
\text { HBsAg }\end{array}$ & $N$ \\
\hline \multicolumn{13}{|c|}{ Universal infant immunization } \\
\hline Belgium* & $1 \cdot 3$ & $0 \cdot 7$ & 1496 & $1 \cdot 1$ & $0 \cdot 7$ & 1175 & 1.9 & $0 \cdot 6$ & 321 & - & - & - \\
\hline Czech Republic $\dagger$ & $2 \cdot 5$ & $0 \cdot 3$ & 2644 & $0 \cdot 2$ & $0 \cdot 3$ & 975 & 1.9 & $0 \cdot 2$ & 1148 & $8 \cdot 3$ & $0 \cdot 8$ & 521 \\
\hline Germany* & $6 \cdot 0$ & - & 6748 & - & - & - & $2 \cdot 9$ & - & 2690 & $8 \cdot 2$ & - & 4058 \\
\hline Italy & $5 \cdot 6$ & $0 \cdot 6$ & 3522 & $1 \cdot 9$ & $0 \cdot 1$ & 1655 & $4 \cdot 3$ & $0 \cdot 9$ & 1266 & $18 \cdot 8$ & $1 \cdot 5$ & 601 \\
\hline Luxembourg* & $2 \cdot 9$ & - & 2678 & $0 \cdot 9$ & - & 1086 & $4 \cdot 3$ & - & 1031 & $4 \cdot 1$ & - & 561 \\
\hline Romania & $20 \cdot 5$ & $5 \cdot 6$ & 1259 & $9 \cdot 4$ & $5 \cdot 1$ & 630 & $23 \cdot 6$ & $7 \cdot 6$ & 276 & $38 \cdot 0$ & $5 \cdot 1$ & 353 \\
\hline Slovakia & $10 \cdot 5$ & $0 \cdot 6$ & 3569 & $7 \cdot 1$ & $0 \cdot 1$ & 1623 & $10 \cdot 6$ & $0 \cdot 9$ & 1270 & $18 \cdot 6$ & $1 \cdot 5$ & 676 \\
\hline \multicolumn{13}{|c|}{ Targeted immunization } \\
\hline Finland & $2 \cdot 7$ & $0 \cdot 2$ & 3083 & $1 \cdot 7$ & $0 \cdot 2$ & 1281 & $2 \cdot 8$ & $0 \cdot 3$ & 1200 & $4 \cdot 3$ & $0 \cdot 2$ & 602 \\
\hline Ireland & $1 \cdot 7$ & $0 \cdot 1$ & 2535 & $1 \cdot 0$ & $0 \cdot 0$ & 877 & $1 \cdot 7$ & $0 \cdot 1$ & 1194 & $2 \cdot 8$ & $0 \cdot 2$ & 464 \\
\hline The Netherlands & $1 \cdot 7$ & $0 \cdot 1$ & 6750 & $0 \cdot 3$ & $0 \cdot 0$ & 1691 & $1 \cdot 4$ & $0 \cdot 2$ & 1810 & $2 \cdot 6$ & $0 \cdot 2$ & 3249 \\
\hline
\end{tabular}

* Samples collected from limited age ranges: Belgium 1-20 years; Germany >16 years; and Luxembourg >3 years.

$\dagger$ Czech Republic compiled the serum bank at the same time as the introduction of universal infant immunization (2001).

WHO, accessed from the 'Health For All' database in August 2007.

\section{Assay standardization}

The methodology and results of the qualitative and quantitative standardization of the antibody and antigen results have been described in detail elsewhere $[14,16]$. In brief, the designated reference centre (Hellenic Centre for Disease Control, Athens, Greece) prepared a panel of 172 sera, which were tested using the Abbott AxSYM system (Abbott Laboratories, Abbott Park, IL, USA) for three markers of HBV infection or vaccination: anti-HBs, anti-HBc and 
HBsAg. The panel included negative, equivocal, low and high positive anti-HBs and anti-HBc antibody titres, thereby enabling the quantitative standardization of the antibody responses. In contrast, only qualitative standardization of $\mathrm{HBsAg}$ results was performed [14].

These panels were distributed to participant laboratories where they were tested for anti-HBs, anti-HBc and HBsAg with the enzyme immunoassay normally used by the participating laboratory [14]. For each antibody marker of HBV infection (i.e. anti-HBs and anti-HBc), national results of testing the reference panel were plotted against those of the reference centre and a regression was performed. The equation of the line-of-best-fit was used as a standardization equation so that local titres could be converted to standard titres. The standardizations of the assays were evaluated quantitatively by determining the fit of the equation using $R^{2}$ (coefficient of determination) and qualitatively by assessing the level of concordance in identifying positive, negative and equivocal results $[14,16]$.

In two countries (Germany and The Netherlands), the serum banks had been tested over a year before the distribution of the reference panel. A method of back-standardization, described in detail elsewhere [16], was performed in these countries in order to standardize their results to project units. In brief, about 150 sera, representative of the different defined statuses (e.g. resolved infection, vaccinated) were randomly selected from the national serum bank and forwarded to the reference centre for testing for the three serological markers of $\mathrm{HBV}$ infection. A regression analysis, as described above, was performed on the two sets of data in order to obtain the appropriate standardization equation [14].

\section{Main serum bank testing}

Each national serum bank was tested using the same validated assay as was used for the reference panel. For the anti-HBc and anti-HBs antibody results, the country-specific standardization equations were used to convert the local quantitative results of the serum survey into standardized reference laboratory units. The reference laboratory cut-offs were used to reclassify qualitatively the standardized quantitative results as negative, equivocal or positive. As testing of the reference panel for HBsAg showed $100 \%$ concordance [14], the HBsAg result was taken as that reported by the national participant.

\section{National HBV testing algorithms}

The HBV testing algorithms employed often reflected whether a universal childhood HBV vaccination programme was in place in those countries (Table 1). Most countries with a vaccination programme tested all samples for anti-HBc and anti-HBs, and then went on to test anti-HBc-positive samples for HBsAg. Germany tested all samples for anti-HBc and antiHBs, but data regarding HBsAg were unavailable due to insufficient volumes of sera for back-standardization. Luxembourg tested all samples for anti-HBs, and then tested anti-HBs-positive samples for anti$\mathrm{HBc}$, but no testing for HBsAg was undertaken.

The HBV testing algorithm for countries without a universal childhood vaccination programme was to test all samples for anti-HBc, and then only test anti-HBc-positive samples for HBsAg (Table 1). In these countries, all anti-HBc negative samples were assumed to be anti-HBs negative as the level of vaccination was very low.

Although the participant countries employed different HBV testing algorithms, we were able to categorize all sera into four groups: no history, vaccinated (only anti-HBs positive), resolved HBV infection (anti-HBc and anti-HBs positive) and acute infection or chronic carriers (anti-HBc positive and $\mathrm{HBsAg}$ positive). It should be noted that the testing algorithms employed would have misclassified as "no history' those who were chronic carriersin Luxembourg as well as successfully vaccinated individuals in Finland, Ireland and The Netherlands.

\section{RESULTS}

At the time of the sera collections, three countries (Finland, Ireland, The Netherlands) had only a targeted vaccination programme of at-risk individuals (e.g. men who have sex with men, or injecting drug users) as well as screening pregnant women for HBsAg (Table 1). The remaining seven countries had introduced universal HBV immunization of infants, and all had included recommendations for adolescent catch-up vaccination, ranging from age 9 years (Romania) to age 17 years (Germany). In six of these seven countries, the main serum banks were collected after the introduction of the mass infant immunization, and one (Czech Republic) at the same time (Table 1).

Of the ten participant countries, the highest prevalence of previous exposure to $\mathrm{HBV}$ infection (i.e. 
anti-HBc positive) was observed in Romania, where $20.5 \%$ of sera were anti-HBc positive (Table 2 ). The percentage exposed increased with age; from $9.4 \%$ in children ( $1-15$ years) to $38.0 \%$ in older adults $(\geqslant 40$ years) (Table 2). Similarly, the prevalence of HBsAg was highest in Romania (5.6\%), although there was no increase in prevalence by age group $\left(\chi^{2}=2 \cdot 7\right.$, $P=0 \cdot 25$ ). The seroprofile for Romania demonstrates that although the reported coverage of infants with HBV vaccination was high ( $>95 \%$ of infants), a large percentage of children had no markers of vaccination (Fig. 1). For example, the reported vaccine coverage of those aged 3-4 years was $98 \%$, but only $63 \%$ had serological evidence of vaccination (i.e. anti-HBc negative and anti-HBs positive). Just under $4 \%$ of this age group had been exposed to HBV infection, of which a third (or $1 \%$ of the total) were $\mathrm{HBsAg}$ positive (Fig. 1).

Of the remaining nine countries, only Slovakia showed previous exposure to HBV infection in the population $>10 \%(10 \cdot 5 \%)$. The proportion of antiHBc-positive samples increased with age, from $7 \cdot 1 \%$ in children to $18.6 \%$ in older adults (Table 2). The proportion of HBsAg-positive individuals in the population was $<1 \%(0.6 \%)$ and similarly increased with age, from $0 \cdot 1 \%$ in children to $1.5 \%$ in older adults $\left(\chi^{2}=15 \cdot 2, P<0 \cdot 001\right)$ (Table 2). Children aged $\leqslant 4$ years would have been targeted by the HBV vaccination of infants introduced with a high reported coverage ( $>95 \%)$, and among 1 -year-olds $85 \%$ were anti-HBs positive (Fig. 1). In contrast, despite the introduction of a catch-up vaccination campaign of 12 -year-olds, $<15 \%$ of adolescents in the $12-15$ years age group had serological evidence of vaccination (Fig. 1).

In Italy, the overall prevalence of past exposure to HBV infection was $5 \cdot 6 \%$, with much higher prevalence of anti-HBc being observed in those aged $\geqslant 40$ years $(18.8 \%)$ than in the younger adult age groups $(1.9 \%$ and $4.3 \%$ respectively) (Table 2, Fig. 1$)$. The carriage of HBsAg also increased with age, from $0 \cdot 1 \%$ in children to $1 \cdot 5 \%$ in older adults $\left(\chi^{2}=17 \cdot 8\right.$, $P<0.001$ ) (Table 2). HBV vaccination of both infants and adolescents was well implemented in Italy as $>80 \%$ of recently targeted age groups (i.e. $1-3$ and 13-15 years) were anti-HBs positive.

In Germany, sera were collected from adults only. Past exposure to hepatitis B was $6 \cdot 0 \%$, and as in Italy, higher anti-HBc was observed in those aged $\geqslant 40$ years $(8 \cdot 2 \%)$ than in the younger adult age groups $(2 \cdot 9 \%)$ (Table 2, Fig. 1). No HBsAg data were reported from Germany, but the proportion of anti$\mathrm{HBc}$ positive-/anti-HBs-negative samples (some of which would have been HBsAg positive) increased with age, from $0 \cdot 7 \%(19 / 2680)$ in younger adults to $1.5 \%(67 / 6058)$ in older adults $\left(\chi^{2}=11 \cdot 47, P<0.001\right)$. Of the participants in Germany targeted by the vaccination recommendation implemented in 1995 (17-20 years age group at the time of the serum collection), only $9.6 \%$ were anti-HBs positive (Fig. 1).

The percentage of the population with a past exposure to HBV infection was $<5 \%$ in the remaining six countries (Belgium, Czech Republic, Finland, Ireland, Luxembourg, The Netherlands), ranging from a minimum of $1.7 \%$ in Ireland and The Netherlands to $2.9 \%$ in Luxembourg (Table 2). The age-specific prevalence of past infection remained $<5 \%$ even in the oldest age groups except in the Czech Republic where $8 \cdot 3 \%$ of older adults (i.e. $\geqslant 40$ years) had serological evidence of past exposure to HBV infection.

In Belgium, where only samples from those aged $<20$ years were tested, nearly $80 \%$ of the youngest children (i.e. $<4$ years) were anti-HBs positive, although coverage was reported as $60 \%$ in this age group. Levels of anti-HBs in those aged 11-12 years targeted by the catch-up recommendations were much lower, but reached $70-80 \%$ in those aged $14-15$ years (Fig. 1). A large proportion of children aged between 4 and 11 years expressed serological markers of vaccination, many of whom would not have been targeted by an HBV vaccination campaign. In Luxembourg, not only was there an important percentage of children with serological markers of $\mathrm{HBV}$ vaccination in age groups not targeted by HBV vaccination, but also in those age groups that were targeted by HBV vaccination, the proportion of children with serological markers of vaccination was much higher than the reported coverage of $49 \%$ in 4-year-olds (Fig. 1).

No universal HBV vaccination policies were in place in Finland, Ireland and The Netherlands (Table 1) and in these countries levels of surface antigen carriage were lower than countries with universal programmes (Table 1). In children, HBsAg carriage was reported to be $0 \%$ in Ireland and The Netherlands and $0 \cdot 2 \%$ in Finland. In Finland, carriage in children was higher than in Italy and Slovakia $(0 \cdot 1 \%$ respectively $)$ and in young adults was higher than in the Czech Republic ( $0 \cdot 2 \%$, Table 1$)$.

No gender differences were observed in any of the countries for past exposure to HBV (i.e. anti-HBc 


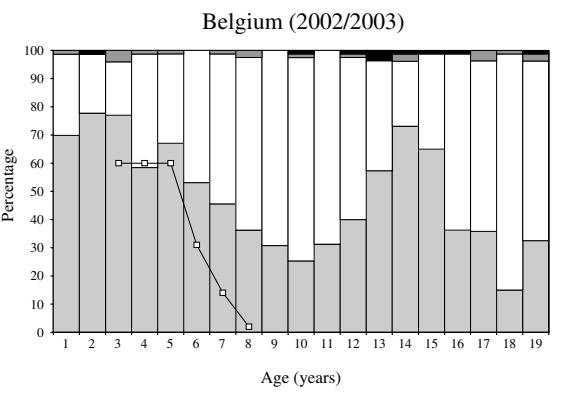

$\stackrel{\text { HBV childhood }}{\longrightarrow}$

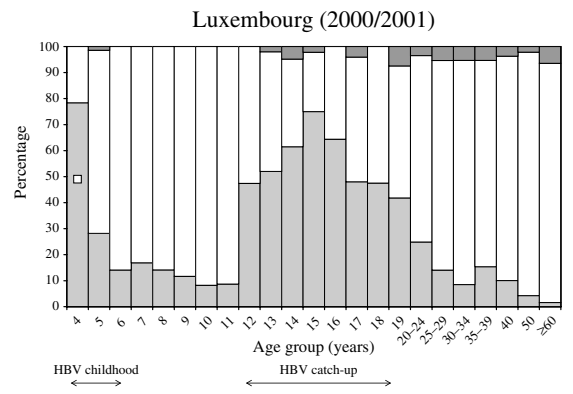

Finland (1997)

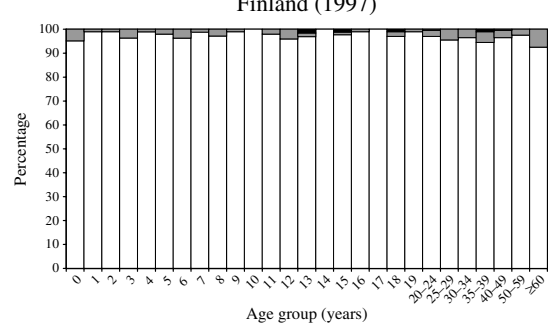

Czech Republic (2001)

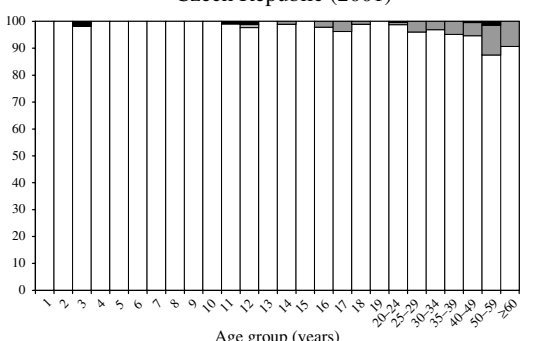

$(2002)$

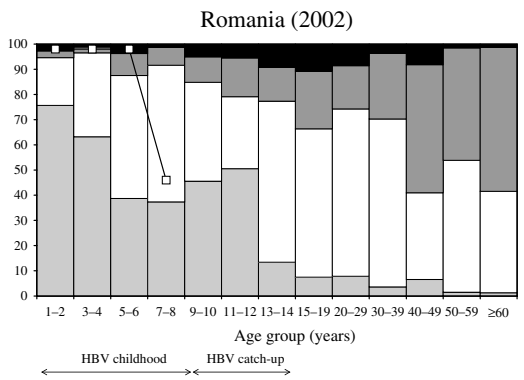

Ireland (2003)

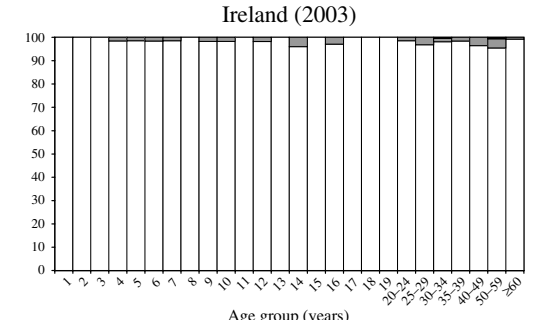

Germany (1998)

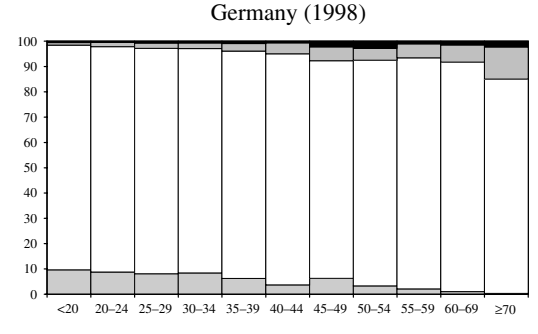

Age group (years)

HBQ catch.up

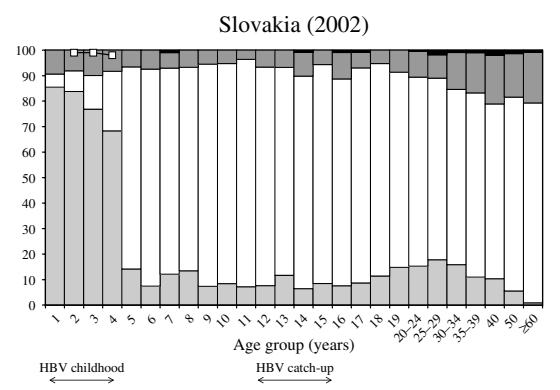

Netherlands (1995/1996)

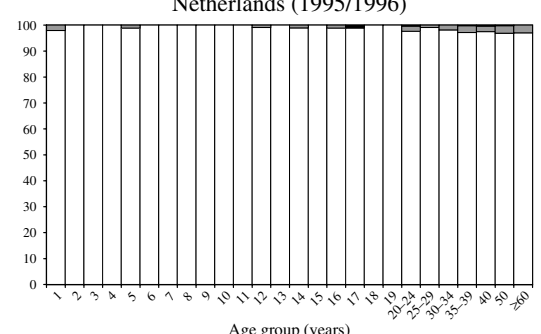

Italy (1996)

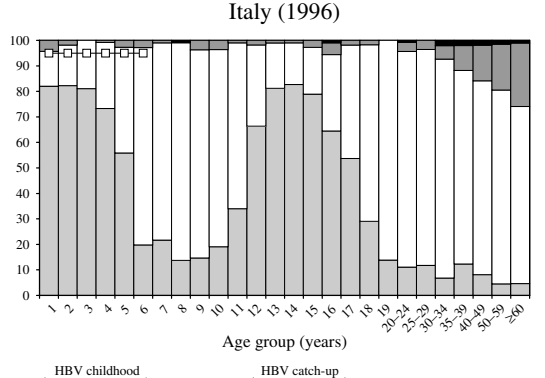

$\stackrel{\text { HBV childhood }}{\longrightarrow}$

Fig. 1. HBV seroprofiles showing reported HBV vaccine coverage in infants ( $\square-\square$ ) and as a histogram the prevalence of samples tested with no history ( $\square$ ), anti-HBspositive only $(\square)$, anti-HBc positive $(\square)$ and HBsAg positive ( $\square$ )* in ten ESEN2 countries, 1996-2003 (* in Germany these samples were anti-HBc positive and anti-HBs negative). Universal infant vaccination programme: Belgium, Czech Republic, Germany, Italy, Luxembourg, Romania, Slovakia. Targeted vaccination programme: Finland, Ireland, The Netherlands. 
positive) in young adults (aged 16-39 years). Statistically significant gender differences in HBsAg carriage were reported only Romania $(9.9 \%$ males, $2 \cdot 9 \%$ females; $\chi^{2}=6 \cdot 27, P=0 \cdot 01$ ). In the five countries with testing algorithms providing serological evidence of vaccination, young women were more likely to be anti-HBc negative and anti-HBs positive than men in Germany and in Slovakia; although only in Germany would any of this age group (17-20 years) have been targeted by a catch-up immunization programme.

\section{DISCUSSION}

We report for the first time a study comparing HBV seroepidemiology in ten European countries, in which possible inter-assay and inter-laboratory variations have been controlled for by a standardization procedure $[14,16]$. Thus, international comparisons of the epidemiology of HBV and in particular the performance of national immunization, control and prevention programmes can be made. The ten countries participating in this study were not randomly selected and they were representative of Europe in terms of geography, vaccination policies and HBV epidemiology [2, 3].

Of the participant countries, the burden of infection was highest in Romania where prevalence of HBsAg carriage $(5.6 \%)$ was in the intermediate range of endemicity (i.e. 2-8\%). Levels of carriage were very much lower in those age groups targeted by the vaccination programme than in those immediately older. However, despite the universal childhood vaccination programme, there is evidence of ongoing transmission of HBV in younger birth cohorts and the reported coverage is much higher than indicated by the serosurvey. In Slovakia and Italy, we have presented serological evidence of the impact of the childhood vaccination programmes as there was high prevalence of anti-HBs in targeted birth cohorts. However, the evaluation of $\mathrm{HBV}$ vaccination programmes is best done by a comparison of the prevalence of vaccinated individuals at different time-points, as age and cohort effects can contribute to changes in the prevalence of individuals with past history of infection [17, 18].

In three countries (Italy, Romania, Slovakia), the proportion serologically identified as vaccinated was lower than the coverage reported in infants. This may be accounted for in older age groups as antibody decay following vaccination has been shown to be rapid within the first year, declining more slowly thereafter
$[19,20]$. Anamnestic responses, conferring immunity to HBV infection, have been reported in individuals with low or undetectable anti-HBs [21, 22], and a report by a European consensus group recommended that no booster doses for immunocompetent children and adolescents [23]. Thus, differences in the reported vaccine coverage and observed prevalence of vaccinated individuals may be of minimal public health importance if vaccine coverage estimates are accurate, which may not be so for all countries. In Belgium, the prevalence of those with serological evidence of vaccination was higher than the coverage reported for many ages, this might be because national coverage was not always measured annually (H. Theeten, personal communication). In Romania, discrepancies between reported vaccine coverage and observed serological correlates of protection were noted not only for HBV, but also for other infections such as measles [24].

Routine immunization of infants will eventually result in a community with a broad-based immunity. However, in many European countries, most infection occurs in young adults so that a stand-alone infant immunization programme will take several decades to eliminate HBV infection in the community [3]. Many European countries, and all the countries with a childhood vaccination programme participating in this study, have included a catch-up component of older children and adolescents in order to more quickly eliminate the infection from the community [4]. The official catch-up policy in adolescents varied from a recommendation to vaccinate, as in Germany, to a campaign entailing mandatory vaccination as in Italy $[25,26]$. In three of the five countries (Germany, Slovakia, Romania), adolescents appear to have been poorly targeted by these catch-up campaigns as evinced by the low proportion of anti-HBs positives in this age group. These findings highlight the difficulties in targeting such a population [25, 27].

Countries with a targeted rather than a universal HBV vaccination programme have cited their verylow HBV endemicity to justify their policy [7]. In this study, the lowest overall prevalence of HBsAg carriage was reported in the three countries with targeted HBV vaccination programmes, although similar prevalence of HBsAg carriage was reported in the Czech Republic where an immunization campaign had been recently implemented. Within Europe, the migration of individuals from high- to low-endemicity countries is having an impact on HBV [11, 28]. Targeted programmes require continued refining and 
improved immunization options to ensure good coverage in at-risk groups [11]. In The Netherlands, an additional programme targeting children with at least one parent coming from a middle- or highendemic country was introduced in 2003 (H. de Melker, personal communication). Nonetheless, the difficulties of implementing targeted vaccination programmes was one of the reasons for the change in vaccination policy recently announced in Ireland [29] and is cited by those advocating the introduction of a universal programme $[28,30]$.

There are some limitations to our study. Two countries did not provide $\mathrm{HBsAg}$ testing data (Germany, Luxembourg), which meant that HBsAgpositive samples could not be identified. In Germany, we reported a prevalence of $1 \cdot 3 \%(86 / 6748)$ anti$\mathrm{HBc}$-positive and anti-HBs-negative samples which represent both HBsAg carriers as well as isolated anti-HBc. In the original study, a mean weighted prevalence of $\mathrm{HBsAg}$ carriage of $0.6 \%$ was reported [31]. The 'isolated anti-HBc' are individuals whose anti-HBs response may have waned, have an occult chronic HBV infection without detectable HBsAg or represent a false-positive reaction [32]. Such samples, although they represent a minority of samples in the sera collections reported here, have been categorized as evidence of a past infection.

Another limitation is that we compared HBV seroepidemiology between countries who compiled serum banks either by residual sera collection or community sampling. Community-based surveys of HBV infection are recommended, as the results are more representative and can be generalized to the population [33]. However, in schoolchildren in Australia, the HBV seroprevalence estimated from residual sera or probability sampling was similar [34]. Other serological studies conducted as part of ESEN2 also did not report any correlation between reported seroprevalence and methods of sera collection [35].

We have demonstrated the utility of serological surveillance in assessing the need for HBV vaccination programmes and their contribution to the evaluation of such programmes where they have been implemented. Serological surveillance, when undertaken in a coordinated and standardized manner and interpreted in the context of data of vaccination programmes and vaccination coverage has provided valuable information for the comparative evaluation of vaccine programmes internationally. Therefore, such initiatives should play an important role in public health in Europe.

\section{ACKNOWLEDGEMENTS}

This work was undertaken with funding from the European Commission (contract number QLK2-CT2000-00542) and from national governments.

\section{DECLARATION OF INTEREST}

None.

\section{REFERENCES}

1. Valsamakis A. Molecular testing in the diagnosis and management of chronic hepatitis B. Clinical Microbiology Reviews 2007; 20: 426-439.

2. Roure C. Overview of epidemiology and disease burden of hepatitis B in the European region. Vaccine 1995; 13: S18-21.

3. Mahoney FJ, Kane M. Hepatitis B vaccine. In Plotkin SA, Orenstein WA, eds. Vaccines, 4th edn. W. B. Saunders \& Co. 2004, pp. 707-743.

4. van Damme P, Vorsters A. Hepatitis B control in Europe by universal vaccination programmes: the situation in 2001. Journal of Medical Virology 2002; 67 : 433-439.

5. Fenner F. Candidate viral disease for elimination or eradication. Bulletin of the World Health Organization 1998; 76: S68-70.

6. World Health Organization. Expanded programme on immunisation global advisory group. Weekly Epidemiological Record 1992; 3: 11-16.

7. van Damme $\mathbf{P}$, et al. Introducing universal hepatitis $B$ vaccination in Europe: differences still remain between countries. Eurosurveillance 2004; 9: 67-68.

8. Mortimer PP, Miller E. Commentary: antenatal screening and targeting should be sufficient in some countries. British Medical Journal 1997; 314: 10361037.

9. O'Connell T, et al. Prevalence of hepatitis B anti-core antibody in the Republic of Ireland. Epidemiology and Infection 2000; 125: 701-704.

10. Pebody RG, et al. Changing epidemiology of hepatitis B infection in Finland. Scandinavian Journal of Infectious Diseases 1999; 31 : 251-254.

11. Hahne $\mathbf{S}$, et al. Incidence and routes of transmission of hepatitis B virus in England and Wales, 19952000: implications for immunisation policy. Journal of Clinical Virology 2004; 29: 211-220.

12. Osborne K, Weinberg J, Miller E. The European SeroEpidemiology Network (ESEN). Eurosurveillance 1997; 2: 93-96.

13. Nardone A, Miller E. Serological surveillance of rubella in Europe: European Sero-Epidemiology Network (ESEN2). Eurosurveillance 2004; 9: 5-7.

14. Kafatos G, et al. The European Sero-Epidemiology Network 2: standardization of assay results for hepatitis B virus. Journal of Viral Hepatology 2007; 14: 260-268. 
15. Andrews NJ, et al. The European Sero-Epidemiology Network: standardizing the enzyme immunoassay results for measles, mumps and rubella. Epidemiology and Infection 2000 ; 125: 127-141.

16. Kafatos G, Andrews N, Nardone A. Model selection methodology for inter-laboratory standardisation of antibody titres. Vaccine $2005 ; 23$ : 5022-5027.

17. Dominguez A, et al. Changes in the sero-epidemiology of hepatitis B infection in Catalonia, 1989-1996. Vaccine 2000 ; 18 : 2345-2350.

18. Da Villa G, et al. Impact of hepatitis B vaccination in a highly endemic area of south Italy and longterm duration of anti-HBs antibody in two cohorts of vaccinated individuals. Vaccine 2007 ; 25: 31333136 .

19. Jilg W, Schmidt M, Deinhardt F. Vaccination against hepatitis B: comparison of three different vaccination schedules. Journal of Infectious Diseases 1989; 160: 766-769.

20. Gesemann M, Scheiermann N. Hepatitis B vaccine boosting among young healthy adults. Lancet 1995; 345: 395-396.

21. West DJ, Calandra GB. Vaccine induced immunologic memory for hepatitis B surface antigen: implications for policy on booster vaccination. Vaccine 1996; 14: 1019-1027.

22. Banatvala JE, Van Damme P. Hepatitis B vaccine - do we need boosters? J Viral Hepatology 2003; 10: 1-6.

23. European Consensus Group on Hepatitis B Immunity. Are booster immunisations needed for lifelong hepatitis B immunity? Lancet $2000 ; 355$ : 561-565.

24. Andrews NJ, et al. Towards measles elimination: measles susceptibility in seventeen European countries and Australia. WHO Bulletin (in press).

25. FitzSimons D, et al. Prevention and control of viral hepatitis through adolescent health programmes in Europe. Vaccine 2007; 25: 8651-8659.
26. Mele A, Stroffolini T, Zanetti AR. Hepatitis B in Italy: where we are ten years after the introduction of mass vaccination. Journal of Medical Virology 2002; 67: 440-443.

27. Zuckerman J, Langer B. Hepatitis B vaccination in a school age population: a feasibility study. Journal of Medical Virology 2005; 75: 47-54.

28. Zuckerman J, et al. Should hepatitis B vaccination be introduced into childhood immunisation programmes in northern Europe? Lancet Infectious Diseases 2007; 7: 410-419.

29. Health Protection Service Centre 2008. (http://www. ndsc.ie/hpsc/A-Z/VaccinePreventable/Vaccination/News/ MainBody,2835,en). Accessed 9 April 2008.

30. Banatvala J, Van Damme P, Emiroglu N. Hepatitis B immunisation in Britain: time to change? British Medical Journal 2006; 332: 804-805.

31. Thierfelder W, et al. Prevalence of markers for hepatitis A, B and C in the German population. Results of the German National Health Interview and Examination Survey 1998. European Journal of Epidemiology 2001; 17: 429-435.

32. Gandhi RT, et al. Response to hepatitis B vaccine in HIV-1-positive subjects who test positive for isolated antibody to hepatitis B core antigen: implications for hepatitis B vaccine strategies. Journal of Infectious Diseases 2005; 191: 1435-1441.

33. Qirbi N, Hall AJ. Epidemiology of hepatitis B virus infection in the Middle East. Eastern Mediterranean Health Journal 2001 ; 7 : 1034-1045.

34. Kelly H, et al. A random cluster survey and a convenience sample give comparable estimates of immunity to vaccine preventable diseases in children of school age in Victoria, Australia. Vaccine 2002; 20 : 3130-3136.

35. Nardone A, et al. The comparative sero-epidemiology of varicella zoster virus in 11 countries in the European region. Vaccine 2007; 25: 7866-7872. 